\title{
TRATAMENTO DE CISTO PARAPROSTÁTICO EM UM CÃO
}

\author{
LÉGA, Elzylene ${ }^{1}$ \\ FARDIN. Valéria ${ }^{2}$ \\ LATARO, Rita Aparecida ${ }^{2}$ \\ CALIMAN, Ana Paula ${ }^{3}$ \\ AgOSTINHO, Juliana Maria Avanci ${ }^{3}$ \\ ZANCHETTA, Rafael Marques ${ }^{3}$ \\ OLIVEIRA, Paula Silva ${ }^{4}$
}

Recebido em: 2011-10-01

Aprovado em: 2011-04-23

ISSUE DOI: $10.3738 / 1982.2278 .478$

\begin{abstract}
RESUMO: O presente trabalho relata o caso clínico de um cão da raça American Pit Bull Terrier, de 7 anos de idade, pesando $27,3 \mathrm{~kg}$, atendido no Hospital Veterinário da FAFRAM, apresentando êmese, disúria, disfagia, disquesia e dor abdominal. Ao exame físico, observou-se escore corporal baixo, desidratação moderada, dor à palpação abdominal e abdômen distendido. Os perfis hematológicos e bioquímicos evidenciaram redução nos parâmetros da série vermelha. À ultrassonografia, foi observada formação cranial à próstata com conteúdo anecóico repleto de celularidade, medindo 14,6 × 9,67cm, sugestivo de cisto paraprostatico. O animal foi submetido a celiotomia para preenchimento do espaço morto cístico com o omento como membrana biológica. À ultrassonografia constatou-se recidiva do quadro sendo o animal submetido à nova cirurgia, realizando a técnica de cauterização do cisto seguida da omentalização convencional. Após 60 dias, ao exame ultrassonográfico, não foi revelado alterações e o animal encontra-se em bom estado.
\end{abstract}

Palavras-chave: Cisto. Próstata. Cão

\section{PARAPROSTATIC CYST TREATMENT IN A DOG}

SUMMARY: This paper reports a case of dog's breed American Pit Bull Terrier, 7 years gold, weighing $27,3 \mathrm{~kg}$, Veterinary Hospital at the FAFRAM, with emesis, dysuria, dysphagia. On physical examination, there was a body score low, moderate dehydration, abdominal pain on palpation and distended abdomen. The hematological and biochemical parameters showed reduction in the red series. At ultrasonography, was observed training cranial to the prostate with anechoic contents full of cells, measuring $14.6 \times 9.67 \mathrm{~cm}$, suggestive of a cyst paraprostatic. The animal was subjected to celiotomy for filling cystic space with omentum as biological membrane. Ultrasonography was found recurrence of the picture with the animal underwent further surgery, performing the technique of cauterization of the cyst followed by conventional omentalization. After 60 days, the ultrasound test, was not revealed changes and the animal is in good condition.

Keywords: Cyst. Prostate. Dog.

\section{INTRODUÇÃO}

A próstata é uma glândula acessória do sistema reprodutor do macho, andrógeno dependente, oval, bilobulada, composta por elementos glandulares e estromais envolvidos por uma cápsula fibromuscular espessa, localizada um pouco abaixo da bexiga e pode quando

\footnotetext{
${ }^{1}$ Docente do Curso de Medicina Veterinária FAFRAM, Ituverava-SP E-mail: lenelega@ hotmail.com

${ }^{2}$ Médica Veterinária do Hospital Veterinário FAFRAM, Ituverava-SP

${ }^{3}$ Aprimorandos do Hospital Veterinário FAFRAM, Ituverava- SP

${ }^{4}$ Biomédica do Hospital Veterinário FAFRAM, Ituverava-SP
} 
acima do seu tamanho normal, comprimir a uretra, dificultando a saída da urina (VANNUCCHI et al., 1997).

De acordo com Krawiec (1994), Paulo et al. (2005) e Apparício et al. (2006), as doenças prostáticas são comuns em cães idosos e podem se manifestar no que se denomina síndrome prostática, com sinais clínicos relacionados ao sistema digestório, urinário e locomotor, podendo estar presentes simultaneamente ou não.

A hiperlplasia prostática benigna (HPB) é a alteração mais comum. Cerca de $100 \%$ dos cães não castrados desenvolvem evidências histológicas de hiperplasia com o avançar da idade (MAHAPOKAI et al., 2000). Os sinais clínicos são tenesmo com fezes em forma de fita, hematúria ou corrimento uretral transparente. Normalmente não apresenta sinais sistêmicos e quando muito intenso, pode provocar o rompimento da musculatura da parede abdominal. No toque retal, nota-se próstata aumentada de volume, simétrica de superfície lisa. (BARSANTI; FINCO, 1992). Dentre outras doenças da próstata, destaca-se a prostatite, que consiste na inflamação da glândula prostática, podendo ocorrer sem uma causa definida manifestando-se com pequena dificuldade de urinar e urina apresentando sangue em quantidade variável. O diagnóstico é feito com base nos exames clínicos, palpação retal e confirmado com a ultrassonografia, sendo que o tratamento consiste na utilização de antibióticos os quais envolvem as quinolonas, que possuem um largo espectro de ação (FELDMAN; NELSON, 1990; BOJARB, 1998). Já as neoplasias malignas são menos freqüentes no cão do que no homem. O diagnóstico é realizado de forma semelhante à hiperplasia benigna, embora os tumores somente são confirmados através de biópsia. No entanto, a imagem da ultrassonografia pode auxiliar na suspeita. O tratamento é feito através da retirada integral da glândula, o que torna a cirurgia delicada, complicada, porém com recuperação satisfatória (FONTELES et al., 2008).

Como a testosterona, pela ação da enzima 5 alfa redutase, transforma-se em dihidrotestosterona, esta última age como um mediador hormonal para o desenvolvimento da hiperplasia, acumulando-se devido a mudanças no catabolismo. Esse processo hiperplásico pode ser facilitado pelos estrógenos, os quais podem aumentar o número de receptores para andrógenos (BARSANTI; FINCO, 1992; FOSSUM, 2002). A hiperplasia prostática benigna se manifesta devido à conversão anormalmente elevada de testosterona em dihidrotestosterona se acumulando de forma não habitual (FOSSUM, 2002). Mesmo no caso de animais idosos, onde há baixa produção de andrógenos, ocorrendo produção aumentada de estrógenos (estroma e estradiol), se desenvolve a hiperplasia (BARSANTI; FINCO, 1992).

Segundo Smith (2008), os cistos prostáticos ou paraprostaticos são frequentemente encontrados em cães com hiperplasia prostática benigna, sendo formados quando os 
canalículos dessa glândula tornam-se obstruídos, conduzindo ao acúmulo de fluidos. Para Raskin; Meyer (2003), os cistos podem manifestar-se como múltiplos e pequenos ou somente como uma estrutura grande. Os pequenos podem ser palpados pelo reto como pequenas áreas flutuantes em uma glândula aumentada assimetricamente. Cistos grandes podem ser palpáveis pelo abdômen ou na região perianal. Os cães podem apresentar-se assintomáticos, ou com secreção uretral sanguinolenta, disúria, tenesmo ou até casos mais graves com dor abdominal, estrangúria, fraqueza e anorexia. Os exames ultrassonográficos, radiográficos e aspiração com agulha fina são os métodos de diagnóstico mais comumente utilizados. A ultrassonografia revela áreas focais ou multifocais, hipo ou anecogênicas. $\mathrm{O}$ exame radiográfico demonstra o aumento da glândula, sendo necessária a radiografia contrastada para diagnóstico diferencial (GUIDO, 2004). A aspiração do cisto caracteristicamente apresenta quantidade variável de fluído com aspecto serossanguinolento a amarronzado. A citologia revela pequena quantidade de células epiteliais de aspecto normal, com raros neutrófilos e hemáceas (RASKIN; MEYER, 2003). Fossum et al. (2002) relataram que o tratamento cirúrgico para pequenos cistos é a castração, inobstante, em cistos grandes deva-se associar a drenagem cirúrgica. Froes et al. (2003) citaram a drenagem percutânea ecodirigida como método pouco invasivo e com raras complicações. Para Hedlund (1997), devido à dificuldade de cura clínica dessa enfermidade, existem várias técnicas cirúrgicas para remoção ou drenagem dos cistos prostáticos ou paraprostáticos tais como, marsupialização, omentalização, e prostatectomia intracapsular subtotal.

Na Medicina Veterinária, a utilização do omento tem ocorrido por suas propriedades de adesão, armazenamento de gordura e preenchimento de espaço morto, contudo seu uso ainda é restrito (GUIDO, 2004).

De acordo com Apparício et al. (2006), a omentalização prostática é um procedimento cirúrgico com mínimas complicações. Pode ser realizada em casos de ocorrência de cistos ou abscessos prostáticos e paraprostáticos. O conteúdo destas estruturas é aspirado, para evitar a contaminação abdominal. A incisão é feita na face ventral da glândula em ambos os lobos prostáticos, na qual, é introduzido o omento dentro das cavidades, em quantidade suficiente para preencher todo o espaço, sem haver comunicação entre os dois lobos e sem circundar a uretra. Esta estrutura é fixada com sutura contínua simples, utilizando fio poliglactina $910 \mathrm{n}$. 3-0 ou n. 4-0, englobando o omento e a cápsula prostática. Esta técnica cirúrgica apresenta baixa incidência de incontinência urinária no período pós-operatório, devido à pequena manipulação da inervação do trígono e da uretra prostática, risco mínimo de ruptura uretral e capacidade do omento de estimular a angiogênese e fornecer suporte vascular. Neste 
contexto, o presente trabalho objetivou relatar um caso de ressecção de um cisto paraprostáticos em um cão, avaliando-se o mesmo no tratamento pós-cirúrgico desta afecção.

\section{RELATO DE CASO}

Um cão da raça American Pit Bull Terrier, de 7 anos de idade, pesando 27,3kg, foi atendido no Hospital Veterinário da FAFRAM, apresentando sinais clínicos de êmese, disúria, disfagia e disquesia. Ao exame físico, observou-se escore corporal baixo, desidratação moderada, dor à palpação abdominal e abdômen distendido, identificando uma massa de consistência firme.

O animal foi submetido à cateterização uretral, através da qual detectou-se dificuldade de passagem da sonda e ausência de urina durante a colheita. $\mathrm{O}$ animal foi então submetido à colheita de sangue para hemograma e dosagens bioquímicas e ao exame ultrassonográfico, o qual revelou formação cranial à próstata com conteúdo anecóico repleto de celularidade, medindo 14,6 x 9,67cm, sugestivo de cisto paraprostático (figura 01), além de bexiga em baixo grau de repleção, deslocada cranialmente e com conteúdo anecóico com partículas em suspensão. Foi realizada punção do cisto guiada por ultrassom, sendo o conteúdo submetido a exame citológico que revelou grande quantidade de neutrófilos. Os perfis hematológicos e bioquímicos evidenciaram redução nos parâmetros da série vermelha.

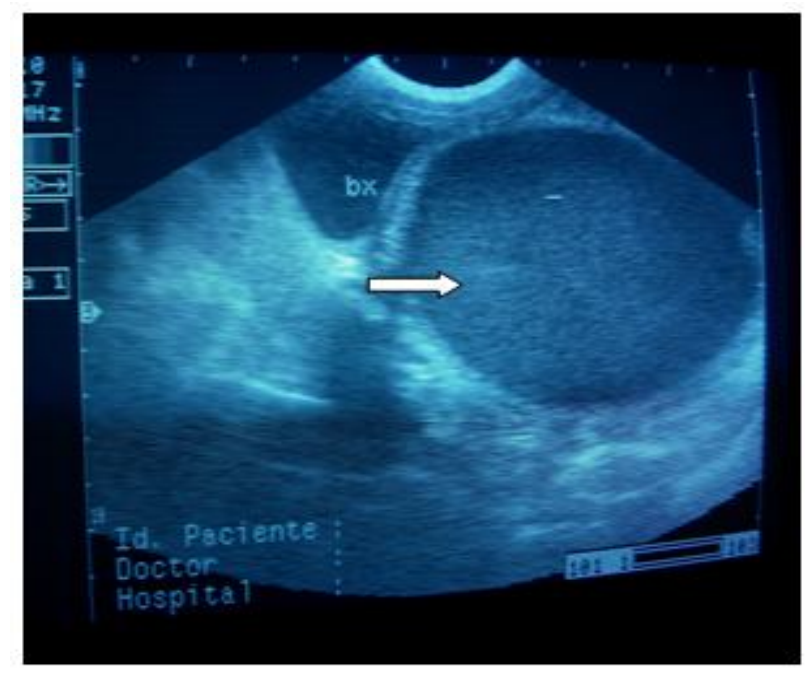

FIGURA 01: Imagem ultrassonográfica de formação anecóica de cisto paraprostático (seta), medindo 14,6 x 9,67cm causando compressão da bexiga (bx) em um cão.

O animal foi submetido à cirurgia, sob indução anestésica com propofol e manutenção com isoflurano. Através de celiotomia pré retroumbilical mediana seguida de paramediana, constatou-se grande quantidade de aderências do cisto em alças intestinais e bexiga. Realizouse punção e incisão na face ventral da próstata para esvaziamento do cisto ( Figura 02 ), com 
auxílio de dois pontos de reparo com categut cromado 2-0, seguido de lavagem com iodo polividona tópico diluído em solução fisiológica. Um fragmento excisado do omento foi colocado de forma a preencher o espaço morto cístico como uma membrana biológica, modificando a técnica descrita por Apparício et al.(2006). Realizou-se cistorrafia com categut cromado 2-0 em padrões Schimieden e Cushing. A celiorrafia foi feita com fio nylon 0 em padrão Sultan; o espaço morto reduzido com nylon 2-0 em padrão Cushing e a dermorrafia com o mesmo tipo de fio em padrão Wolf. Orquiectomia bilateral pré-escrotal foi realizada de forma concomitante.

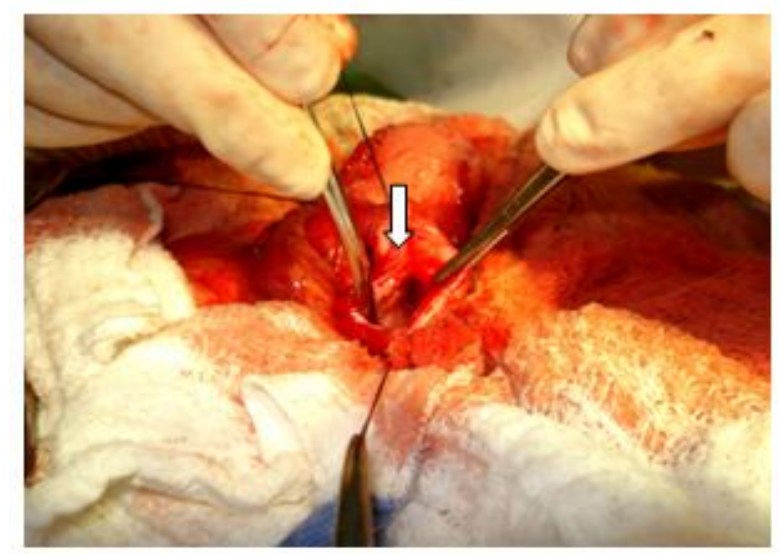

FIGURA 02: Imagem fotográfica de cisto paraprostático (seta) em um cão da raça American Pit Bull Terrier submetido à técnica de omentalização.

O pós-operatório incluiu enrofloxacina $(7,5 \mathrm{mg} / \mathrm{kg})$ BID por 15 dias, meloxican $(0,1 \mathrm{mg} / \mathrm{kg})$ SID, 5 dias; Prosten Plus $\AA^{5}$ BID, 60 dias; dipirona $(28 \mathrm{mg} / \mathrm{kg})$ BID, 7 dias e curativo local com rifamicina TID, 10 dias, acompanhado por ultrassonografias semanais, constatando-se recidiva do quadro 30 dias após a cirurgia.

O animal foi submetido a um novo procedimento cirúrgico para técnica convencional de omentalização prostática (APPARÍCIO et al., 2006), com prévia punção para esvaziamento do cisto, ressecção de fragmento da parede livre de aderências, cauterização da face interna da parede restante e omentopexia com fio categut cromado 2-0. O pós-operatório foi semelhante ao anterior. Após dois meses, o animal retornou para vacinação anual contra viroses, sendo submetido a novo controle ultrassonográfico sem evidência de sinais prostáticos, encontrando-se em bom estado de saúde.

\section{RESULTADOS E DISCUSSÃO}

A espécie animal acometida no presente relato concorda com Mattoon e Nyland (2002); Nelson; Couto (2001); Kay (2003) que descrevem as doença s prostáticas comuns em

\footnotetext{
${ }^{5}$ Pygeum africanum $25 \mathrm{mg}$ e extrato de urtiga 300mg.
} 
cães e raras em gatos. Ressalta-se também a idade do animal de sete anos, concordando com Apparício et al. (2006), Paulo et al. (2005) e Krawiec (1994) que relatam as doenças paraprostáticas normalmente acometendo animais de meia idade.

Os sinais clínicos demonstrados pelo animal como emese, disúria, disquesia, distensão abdominal são compatíveis com os relatados por Di Santis, Amorim e Bandarra (2001); Kustritz; Klausner (2004) e Hedlund (2002).

O exame ultrassonográfico, no presente caso, mostrou ser uma técnica eficaz na avaliação da próstata e diagnóstico de cisto paraprostático. De acordo com a literatura consultada, a ultrassonografia se sobressai como o método mais comumente utilizado e eficaz para tal diagnóstico (KRACWIEC, 1994; MURASHIMA JÚNIOR, 2001; KUSTRITZ; KLAUSNER, 2004).

O cisto paraprostático se difere do cisto prostático por apresentar-se adjacente á próstata e não como parte de seu parênquima (HEDLUND, 2002; KEALY; McALLISTER, 2005; NYLAND; MATTON, 2005), o que pode tornar o procedimento cirúrgico mais seguro visto não ter risco de envolvimento uretral. No entanto, pela presença de polimorfonucleares no conteúdo cístico, o risco de peritonite deve ser considerado (APPARÍCIO et al., 2006).

Os exames hematológicos complementares não demonstraram evidências de alterações sistêmicas graves, com exceção da série vermelha que mostrou parâmetros discretamente diminuídos. Estes achados concordam com Barsanti; Finco (1997) que citam inalteração destes exames na doença crônica, alterando-se apenas em casos de abscedação.

A técnica de utilização do omento como membrana biológica de preenchimento de espaço morto não mostrou resultado satisfatório, visto que apesar de promover aderência na parede interna, não houve drenagem do líquido cístico por dificuldade de suporte vascular (APPARÍCIO et al., 2006). Assim, após recidiva, optou-se pela técnica de omentalização convencional do cisto, tendo bons resultados, sendo o procedimento realizado de maneira semelhante àquele descrito por Bray et al. (1997) apud Pimentel (2008).

Nascimento (2009) descreveu a técnica de prostatectomia como método eficaz em casos de cisto paraprostáticos. Porém, Fossum et al. (2002) relataram que, para pequenos cistos, o tratamento de eleição é a castração e Froes et al. (2003) defenderam a drenagem percutânea ecodirigida por ser pouco invasiva e com mínimos riscos de complicações. No entanto, a castração deve ser considerada como tratamento preventivo à hiperplasia prostática e deve ser realizada em todos os casos em que há aumento de volume da glândula, com intuito de diminuir a produção de testosterona (BASINGER, 1987). Por outro lado, a drenagem percutânea deve ser cautelosa pelo risco de contaminação da cavidade abdominal com células inflamatórias, além da possibilidade de recidivas. 


\section{CONCLUSÃO}

As afecções prostáticas são comuns em cães idosos, sendo que a ultrassonografia é uma técnica acurada no diagnóstico diferencial de tais afecções.

A técnica convencional de omentalização de cisto paraprostático teve prognóstico superior àquela em que se utilizou o omento como membrana biológica.

\section{REFERÊNCIAS}

APPARÍCIO, M. et al. Omentalização prostática em cães. Brazilian Journal of Veterinary Research and Animal Science, v.43, n.6, p.754-761, 2006.

BARSANTI, J.A.; FINCO, D.R. Moléstias prostáticas do cão. In: ETTINGER, S.J. Trat. de Med. Int. Vet. Califórnia: Manole Ltda., 1992, p. 1941-63.

BASINGER, R.R. Surgical management of prostatic diseases. Comp. Small Anim: Cont. Educ. Art. v. 9, n. 2, p. 993-999, 1987.

BOJRAB, M.J. Mecanismos da moléstia na cirurgia dos pequenos animais. 2.ed. São Paulo: Manole, 1998. p.629-636.

BRAY, J.P. et al. Partial resection and omentalization: a new technique for management of prostatic retention cysts in dogs. In: PIMENTEL, A.S. Uso da técnica de omentalização no tratamento de cisto paraprostático em cão (Canis familiaris): relato de caso. Monografia (Latu sensu). Universidade Castelo Branco. Rio de Janeiro, 2008

DI SANTIS, G.W.; AMORIM, R.L.; BANDARRA,E. P. Aspectos clínicos e morfológicos das alterações prostáticas em cães- revisão. Revista de educação continuada CRMVSP, São Paulo, v.4, fasc. 2, p.46-52, 2001.

FELDMAN, E; NELSON, R.W. Canine and feline endocrinoly and Reproduction. 1990. p.481-488. Ed. W. Bsalders company.

FONTELES, Z.G.C.et al. Avaliação ultra-sonográfica e radiográfica em um cão com prostatomegalia submetido à prostatectomia total: relato de caso. 2008. Disponível em: http://www.sovergs.com.br/conbravet2008/anais/cd/resumos/R0208-3.pdf Acesso em: 21 set. 2010.

FOSSUM, T. W., HEDLUND, C. S., HULSE, A.D. et al. Cirurgia de pequenos animais. São Paulo: Roca, 2002. 1114 p.

FROES, T. R.et al. Ultra-sonografia intervencionista - drenagem percutânea de lesões cavitárias e cistos prostáticos em cães. Clinica veterinária, São Paulo, n. 47, p. 34-40.

GUIDO, M. C. Ultra-sonografia do aparelho reprodutor masculino. In: CARVALHO C. F. Ulta-sonografia em pequenos animais. São Paulo: Rocca, 2004. p. 213. 
HEDLUND, C. Cirurgia do Sistema Reprodutivo e Genital; In: FOSSUM, T. Cirurgia de pequenos animais. São Paulo: Roca, 2002. C.23.p.611-618.

KAY, N. D. Prostatopatias. In: BIRCHARD S. J., SHERDING R. G. Manual Saunders Clínica de Pequenos Animais. São Paulo: Rocca, 2003. 973-80p.

KEALY, K. J., Mc ALLISTER, H. O Abdome: radiologia e ultra-sonografia do cão e do gato. 3.ed. Barueri: Manole, 2005. 131-36p.

KRAWIEC, D.R. Study of prostatic of disease in dogs: 177 cases (1981-1986). J. Am. Vet. Med. Assoc., v.200, n.8, p.1119-22, 1992.

KRAWIEC, D.R. Canine prostate disease. Journal of the American Veterinary Medical Association, v.2004, n.10, p.1561-1564,1994.

KUSTRITZ, M.V.R.; KLAUSNER, J. S. In: ETTINGER S. J.; FELDMAN E. C. Tratado de medicina interna veterinária doenças do cão e do gato. 5 ed. v.2. Rio de Janeiro: Guanabara Koogan, 2004. 2294-2325p.

MAHAPOKAI, W. et al. Models for stuying benign prostatic hiperplasia. Prostate Cancer and Prostatic Diseases, v. 3, p. 28-33, 2000.

MATTOON, J. S.; NYLAND, T. G. Small Animal Diagnóstic Ultrasound. 2.ed. Philadelphia, PA: W B Saunders Company, 2002. 250-266 p.

MURASHIMA JÚNIOR, J.C. Mensuração da próstata por ultra-sonografia transabdominal, e sua associação com a massa corpórea de cães adultos e clinicamente sadios. 2001. 47p. Dissertação (Mestrado) - Faculdade de Medicina Veterinária e Zootecnia, Universidade Estadual Paulista. Botucatu.

NASCIMENTO, V.R.S. Prostatite bacteriana crônica e cistos prostáticos em cães - relato de caso. Monografia (Latu sensu). Universidade Federal Rural do Semi-Árido. 2009.

NELSON, R. W. COUTO, C.G. Medicina interna de pequenos animais. 2ed. Rio de Janeiro: Guanabara Koogan , 2001, cap. 62. 718-22p.

PAULO, N.M. et al. Biomembrana de látex natural (heveabrasilensis) com polilisina a $0,1 \%$ para herniorrafia perineal em um cão. Acta Scientiae Veterinariae, v.33, n.1, p.79-82, 2005.

PAULO, N.M. et al. Drenagem percutânea de cisto paraprostático, guiada por ultra-som em um cão. Acta Scientia Veterinariae.v.33, n.1, p.325-328, 2005.

RASKIN, R. E., MEYER, D. J. Atlas de citologia de cães e gatos. São Paulo: Rocca, 2003. p. 253-255.

SMITH, J. Canine prostatic disease: a review of anatomy,pathology, diagnosis and treatment. Theriogenology, v.70, p.375-383, 2008.

VANNUCCHI, C.I.; et al. Afecções prostáticas em case: sinais clínicos, diagnóstico e tratamento. Clínica Veterinária, ano II, n.11, p. 37-42, 1997. 